\title{
DELINQUÊNCIA FEMININA, CRIMINOLOGIA E POLÍTICA CRIMINAL: UMA ABORDAGEM CRÍTICA COM PERSPECTIVA DE GÊNERO
}

\section{DELINCUENCIA FEMENINA, CRIMINOLOGÍA Y POLÍTICA CRIMINAL: UN ABORDAJE CRÍTICO CON PERSPECTIVA DE GÉNERO}

\author{
${ }^{1}$ Gabriela Souza Cezimbra \\ ${ }^{2}$ Rosane Beatris Mariano da Rocha Barcellos Terra
}

\section{RESUMO}

$\mathrm{O}$ fato de a delinquência feminina ser consideravelmente menor que a masculina tem estimulado poucos trabalhos neste sentido. Ainda assim, há muitas explicações para estas diferenças entre as taxas de delinquência dentro dos estudos criminais, que se alteram de acordo com o período social e histórico. Este artigo objetiva dar um enfoque à mulher como autora de delitos, por meio da retomada dos principais estudos criminais a respeito do tema. Serão apresentadas teorias tradicionais e críticas para compreender essa criminalização inferior, buscando-se refletir se ser menos criminalizada é vantajoso ou não para a mulher. Ademais, se busca verificar por qual delito a mulher é mais penalizada, construindo-se breves considerações a respeito da dura política criminal antidrogas, a partir de uma perspectiva crítica e de gênero. Por fim, se utiliza de uma metodologia mista de método e abordagem que compreende pesquisas bibliográficas, bem como apreciação e análise de dados estatísticos sobre a reclusão feminina.

Palavras-chave: Delinquência feminina, Perspectiva de gênero, Política criminal

\section{RESUMEN}

El facto de la delincuencia femenina ser considerablemente menor que la masculina ha estimulado pocos trabajos en esto sentido. Todavía, hay muchas explicaciones para estas diferencias entre las tasas de delincuencia en los estudios criminales, que cambian de acuerdo con el período social e histórico. Este artículo objetiva volver la mirada a la mujer autora de delitos, a través de una retomada de los principales estudios criminales a sobre el tema. Van ser presentadas teorías tradicionales y críticas para comprender esa criminalización inferior, buscando reflexionar si ser menos criminalizada es ventajoso o no para la mujer. Además, buscase verificar por cual crimen la mujer es más penalizada, haciendo unas breves consideraciones a respecto de la dura política criminal anti-drogas, desde la perspectiva crítica y de género. Para eso, utilizase de una metodología mixta de método y abordaje- que comprende pesquisas bibliográficas, bien como análisis de datos estadísticos a respecto de la reclusión femenina.

Palabras-claves: Delincuencia femenina, Perspectiva de género, Política criminal

\footnotetext{
${ }^{1}$ Mestre em Estudios Interdisciplinares de Género pela Universidad de Salamanca - USAL, Espanha. Graduada em Direito pelo Centro Universitário Franciscano - UNIFRA, Santa Maria - RS (Brasil).

E-mail: cezimbra.gabriela@ hotmail.com

${ }^{2}$ Doutora em Direito pela Universidade de Santa Cruz do Sul, UNISC, Capão da Canoa - RS (Brasil) Professora do Centro Universitário Franciscano - UNIFRA, Santa Maria - RS (Brasil).

E-mail: rosanebterra@yahoo.com.br
} 


\section{INTRODUÇÃOO}

Desde os relatos mais remotos da história da humanidade, a mulher costumeiramente aparece discriminada em razão do seu sexo. Na Espanha pré-romana, como rara exceção a essa regra, se apresentam raros registros de sociedades matriarcais ${ }^{1}$, mas a regra do mundo ocidental é o sistema patriarcal por excelência. Tratada como inferior, a mulher não tinha poderes e direitos políticos, voz, liberdade, espaço público nem reconhecimento de suas capacidades.

Toda esta situação de inferioridade tem reflexos também no direito penal e na criminologia. O crime foi concebido e recepcionado com vinculação, mais específica ao agente masculino, enquanto que sequer percebia e/ou avaliava a mulher como capaz de ser sujeito ativo dos delitos (apenas quando as consideravam anormais biologicamente, fisiologicamente ou psicologicamente). Havia que se buscar nas mulheres que delinquiam algo atípico que tinha relação com a natureza dos seus instintos estimulados pela desconformidade com os padrões de socialização que marcavam os valores "naturalmente" femininos (ABREU, 2014).

Isso levou a explicar o comportamento delitivo da mulher desde uma perspectiva individual, de caráter bioantropológico ou psicológico, nos quais o sexo e os processos biológicos próprios da mulher são as bases sobre as que se sustentaram as explicações da delinquência feminina, considerando a atividade criminal feminina como uma anormalidade, em contraste com o arquétipo feminino biológico e social dominante (SERRANO TÁRRAGA y GONZÁLEZ, 2006).

Ainda que houvesse alguns poucos personagens ${ }^{2}$ lutando pela liberdade e igualdade da mulher, apenas com os movimentos feministas do início do século XIX (primeira onda, com direitos políticos), fins dos anos 60 (segunda onda) e anos 90 (terceira onda), que as reivindicações das mulheres começaram a ter força, conquistando direitos e mais liberdades. Ou seja, é cediço que há muito pouco tempo que a mulher começou a ser considerada sujeito de direitos, e não apenas objeto de direitos.

Por meio destes movimentos de libertação (principalmente nos finais dos anos 60), que aprecem as manifestações feministas nos estudos do direito penal e criminologia,

\footnotetext{
1 Em alguns pueblos na Espanha pré-românica, como por exemplo asturios, vascos e ibicencos, encontava-se "la covada", que é considerada como uma das manifestações de um tipo de família baseado no matriarcado (GÁRATE, Justo. La covada pirenaica. Patrañas y fantasías).

2 Mary Wollstonecraft (1759-1797), com sua obra "Reivindicação dos direitos da Mulher" (1792) e John Stuart Mill (1806-1873), quem, junto a sua mulher Harriet Taylor Mill (1807-1856), publicou “A submissão da mulher", em 1869 são dois raros exemplos.
} 
aproveitando as contribuições dos conceitos de gênero para vincular a condição da mulher como vítima e autora de delitos a partir de contextos sociais em que estão inseridas.

É neste linha de raciocínio que o presente trabalho se estrutura e apresenta como temas centrais: a crítica das teorias criminológicas tradicionais que abordam a mulher na posição de autoras de delitos; a compreensão crítica e sociológica do desvio para analisar dados estatísticos da criminalização feminina e compreender as razões pelas quais até hoje delinquem menos, buscando refletir se isso é vantajoso ou não para elas; e o estudo das atuais políticas criminais, a partir da análise do principal delito pelo qual a maioria das mulheres criminalizadas responde.

Para tanto, assume-se uma postura criminológica crítica, na medida em que se passa a posicionar-se contra a atuação do controle penal do Estado, bem como em relação a uma perspectiva feminista que trabalha com o conceito de gênero e a necessidade de desconstrução de seus estereótipos, contra o controle patriarcal da sociedade.

Nesse desiderato, mediante uma atenção às mulheres autoras de delitos - se utilizando da perspectiva de teorias críticas do Direito Penal e teorias feministas - o problema de pesquisa consiste em denunciar as relações convergentes entre o controle penal e o patriarcal.

Como objetivos específicos, se busca: a) fazer uma aproximação histórica da abordagem das mulheres autoras de delitos, almejando completar um vazio histórico a respeito da delinquência feminina; b) com o marco dos estudos da criminologia crítica e explicações sociológicas do desvio, compreender porque até hoje delinquem menos; c) questionar se o fato de ser menos criminalizadas é vantajoso para as mulheres; d) analisar por quais crimes são mais criminalizadas, buscando uma reflexão crítica a respeito da atual política criminal contra as drogas.

A opção teórica metodológica do estudo busca romper com as heranças recebidas do positivismo. Desse modo, os fenômenos sociais estudados no presente trabalho apenas podem ser explicados de uma maneira transdisciplinar. A investigação seguirá o rumo do método da Criminologia crítica a partir da avaliação do fenômeno criminal (utilizando procedimentos indutivos), propondo soluções marcadas pelos princípios gerais da socialização, controle formal e informal, perspectiva de gênero (procedimento dedutivo de ordem sociológica).

Ademais, este artigo requer um trabalho de indagação bibliográfica, para verificar o tratamento dispensado às mulheres delinquentes nos estudos criminológicos. Ademais, se pretende observar os dados estatísticos de sistemas penitenciários, com a finalidade de ilustrar de maneira quantitativa a criminalização feminina. Finalmente, se passa a uma análise 
qualitativa, com o propósito de verificar os delitos pelos quais são massivamente criminalizadas e propor uma reflexão sobre política criminal.

Nessa seara, levando-se em conta as diversas dimensões sobre as quais se indagará no curso do trabalho, a metodologia será mista, atendendo as várias frentes em que se move e, para tanto, segue-se para o primeiro tópico que dará guarida as construções postas acima.

\section{O “GENDER GAP” NA DELINQUÊNCIA. POR QUE HÁ MAIS HOMENS}

\section{CRIMINALIZADOS?}

A constante desproporção entre as taxas delitivas entre homens e mulheres fenômeno denominado em inglês "gender gap" (Rodríguez, 2009, p.166) _ tem sido explicado por várias teorias, que se alteram de acordo com os contextos históricos e sociais.

Os primeiros estudos a cerca da mulher delinquente se dão a partir de teorias individuais de cunho biológico e psicoanalítico. Antes mesmo de Lombroso (1893), conhecido como o pai da criminologia empírica, já eram apreciados alguns estudos a respeito da baixa delinquência feminina, centrados nos aspectos biológicos. A delinquente não era considerada normal, sendo encontrados elementos naturais e fisiológicos para qualificá-la como diferente e inferior (capacidade cranial, cérebro menos desenvolvido, condições hormonais, etc.)

Assim, como já referido anteriormente, os principais estudos reconhecidos, antes de Lombroso (1893), a respeito da ligação das condições biológicas com o delito foram feitos por Pauline Tarnoswsky (1889), Pyke (1876), Van de Warker (1895), Bean (1906) e Paul Broca (1861).

Tarnoswsky (1889), identificou diferenças biológicas na capacidade cranial entre grupos de mulheres assassinas e as não delinquentes. Neste mesmo sentido, Pyke (1876) definiu que o fato de a mulher se situar em um nível de desenvolvimento genético inferior ao adequado, a levaria a delinquir. Ainda, Van de Warker (1895) afirma que o homem comete delitos fundamentalmente quando pobres, enquanto que a mulher cometeria por desequilíbrios mentais.

Nessa mesma senda de caracterizações e diferenciações apresenta-se a concepção de Bean (1906) que, ao estudar a estrutura cerebral, comparou o cérebro de distintas raças e de homens e mulheres, chegando a afirmar que dentro de cada raça, a mulher possuía uma 
inteligência menos desenvolvida que o homem. Broca (1861) considerava que o cérebro feminino havia se degenerado por meio do tempo, devido à utilização cerebral parcial imposta às mulheres pelas estruturas sociais existentes (SERRANO TÁRRAGA Y GONZÁLEZ, 2006).

As conclusões destes estudos eram comuns e legitimavam uma inferioridade da mulher infratora de modo que apresentavam e identificavam diferenças biológicas entre as mulheres "normais", que cumpriam com todos os estereótipos impostos para seu gênero, e as delinquentes. Estas últimas teriam uma condição biologicamente deficiente, que não permitiria assimilar a ordem social imposta.

Ainda a respeito das teorias individuais biológicas, da investigação empírica de Lombroso e Ferrero (1893), resultam as explicações bioantropológicas do delito ${ }^{3}$. Estes autores aplicam sua conhecida teoria do "criminoso nato" às delinquentes femininas, chegando à conclusão de que as mulheres eram naturalmente inferiores aos homens de maneira geral, mas as delinquentes eram ainda menos evoluídas. Desta forma, por não haver desenvolvido desde sua origem, e pelo fato de ser delinquente, a mulher situava-se em um estágio evolutivo autenticamente inferior (Serrano Tárraga y González, 2006). Este nível tão baixo de progresso incapacita a maioria das mulheres para cometer delitos, sendo - para as teorias Lombrosianas- este o motivo que explica a baixa taxa de delinquência feminina.

Esta evolução inferior é explicada, em alguns trechos do estudo destes autores, como sendo causa da inatividade da mulher frente ao varão que teria uma origem biológica: "a imobilidade do óvulo comparada com a do espermatozoide” (SERRANO TÁRRAGA Y GONZÁLEZ, 2006, p. 164).

Neste sentido, para estes estudos, a mulher é portadora de características naturais e biologicamente imutáveis, como o instinto maternal. Tais características se apresentam no seu rol social, e confirmam a verdadeira natureza da mulher, fazendo com que os comportamentos desconformes com essas pautas devam ser considerados anormais.

3 As teorias bioantropológicas da criminologia, inauguradas por Cesare Lombroso, objetivavam fixar critérios científicos de investigação
das causas da delinquêencia com base no estudo do biótipo do criminoso. (MATOS, 2010, p. 1) 
Assim sendo, a delinquência feminina aparece definida por uma dupla anormalidade: biológica e social, na medida em que sua criminalidade representa uma prática masculinizada e imprópria para seu sexo (Serrano Tárraga y González, 2006). Visto sob uma outra perspectiva tem-se que, para o homem, a anormalidade aparece na maioria das vezes relacionada apenas com as normas legais, enquanto que para a mulher é anormal legalmente e inclusive socialmente, o que a faz comparável com um "monstro" (LOMBROSO e FERRERO, 1927, p. 122).

Outras explicações que envolvem o desenvolvimento sexual tentam identificar as razões pelas quais as mulheres delinquem menos, a partir de estudos hormonais. Para estes estudos, a maior delinquência masculina se deve ao fato de o homem possuir mais hormônios andrógenos, e fundamentalmente a testosterona, que seria responsável pela agressividade. Há também pesquisas que ligam os próprios ciclos menstruais a uma predisposição maior da mulher para delinquência nestes períodos ${ }^{4}$, sempre buscando condição fisiológica e de anormalidade para a delinquência feminina.

Ademais, outras explicações de pesquisa genética tentaram explicar a diferença entre os índices de delinquência masculina e feminina, ao supor que o cromossoma Y seria o principal responsável pela agressividade, o que faria os homens mais predispostos ao cometimento de delitos (MURILLO, 1990).

Da mesma forma, foram igualmente importantes para o entendimento de criminalidade feminina na época os estudos de Freud (1959), que protagonizou as teorias psicoanalíticas do delito. Para Freud (1959), a mulher somente poderia alcançar o desenvolvimento do seu ego a partir de um ambiente harmônico, caracterizado pelo equilíbrio das relações afetivo-familiares, e pelo desempenho de seu papel de esposa e mãe (SERRANO TÁGARRA Y CONZÁLES, 2006).

Já as teorias psiquiátricas são realizadas por intermédio de dois enfoques: individual e social. O primeiro trabalha o delito feminino como um transtorno mental, uma enfermidade que faz a mulher delinquir. Já a segunda perspectiva, explica a pouca existência de delinquência feminina por uma perspectiva mais social, dizendo que vai ser uma implicação do trato diferenciado dos homens e das mulheres por parte dos sistemas de controle (SERRANO TÁGARRA Y CONZÁLES, 2006).

\footnotetext{
4 Esta relação adquire importancia com a publicação do artigo de de Middleton em 1933: “Is There a Relation Between Kleptomania and Female Periodicity in Neurotic Individuals?".
} 
Este trato diferencial que aborda a supramencionada teoria refere-se substancialmente à maior quantidade de mulheres diagnosticadas com problemas mentais em comparação aos homens. Estão submetidas a um maior número de internações e consideradas menos capazes mentalmente de cometer os delitos. Sobre isso, destaca-se o que diz a autora Carol Smart (1976):

\begin{abstract}
A segunda proposição se resolve ao redor da ideia de que a enfermidade mental para as mulheres representa uma forma equivalente ou alternativa ao comportamento criminal. Esta última proposição pressupõe isso, em razão de que, estatisticamente falando, mais mulheres são diagnosticadas como enfermas mentais e depois categorizadas como criminais. A enfermidade mental é uma forma de conduta desviada apropriada para as mulheres, cumprindo para elas as mesmas necessidades ou funções que a conduta delitiva tem para os homens." (SMART, 1976, p. 146)
\end{abstract}

Smart (1976) assinala a existência de uma tendência entre os psiquiatras a diagnosticar as mulheres como neuróticas em uma maior proporção que aos homens. Segundo a autora, se uma mulher manifesta alguma doença, o profissional psiquiátrico tende a pensar que é um invento e não uma autêntica enfermidade, sendo ela uma neurótica, o que torna mais apropriado que a mulher seja internada em estabelecimentos psiquiátricos (manicômios) do que em prisões comuns.

O princípio da influência sociológica nas teorias criminais, mantém heranças e raízes biológicas. Seria conceber que misturam as duas, percebendo o delito como "um fenômeno natural e social”' ao mesmo tempo (ABREU, 2014, p.40).

Para Thomas (1907), por exemplo, a mulher tem seus próprios instintos biológicos maternos, para o cuidado e para o amor. Nesse sentido, a família é uma instituição de controle para que estes instintos sejam cumpridos na sua socialização. O comportamento criminal feminino, portanto, está relacionado com a perda da unidade familiar tradicional, o que origina na mulher uma situação desconcertante, devido à perda do marco adequado para controlar plenamente o seu instinto biológico-amoroso (SERRANO TÁRRAGA Y GONZÁLEZ, 2006).

\footnotetext{
${ }^{5} \mathrm{O}$ texto em língua original diz: "The second proposition resolves around the idea that mental illness for women represents an equivalent or alternative form of behaviour criminality. The latter proposition presupposes that because statiscally speaking, more women are diagnosed as mentally ill than become categorized as criminal, mental illness is a form of deviant behaviour appropriate to women, fulfilling for them the same needs or functions as criminal behaviour does for men." (SMART, 1976: 146).
} 
No mesmo sentido da teoria individualista com projeção social, temos o autor Otto Pollack (1961) que, seguindo uma mesma corrente de influencia Lombrosiana, introduz o conceito de "cavalheirismo" no estudo da situação da delinquência feminina. Para ele, a baixa taxa de criminalidade feminina poderia ser explicada como sendo consequência de uma atividade criminal submergida e com consideração social favorável, com o qual sua delinquência não costumaria ser detectada pela polícia. Ademais, mesmo naqueles casos em que se denuncia, a mulher teria um trato favorável em comparação ao varão por parte dos órgãos judiciais (SERRANO TÁRRAGA Y GONZÁLEZ, 2006).

A respeito da teoria de Pollack, nos conta Murillo (1990):

\begin{abstract}
A baixa taxa de criminalidade feminina poderia se explicar como uma consequência simultânea, tanto de uma atividade criminal disfarçada como de sua favorável consideração social, de tal maneira que além de sua criminalidade não costumar ser detectada pela polícia em aqueles casos que se denuncia, ainda se outorga um trato mais favorável que ao varão por parte do "Sistema de Justiça penal" - prática conhecida como cavalheirismo" (MURILLO, 1990, p. 71)
\end{abstract}

O que resta claro com esta percepção é um perfil sempre paternalista do Direito penal, traduzido nesta consideração de incapacidade da mulher em assumir a responsabilidade por seus atos, devendo sempre ser protegida e tratada com preferência.

Já com o marco da segunda onda dos movimentos de libertação feminista, no final dos anos sessenta, é que surge o conceito de gênero ${ }^{7}$ e, com ele, a solidificação de estudos mais aprofundados que levam em conta as diferenças sociais e culturais de formação do gênero feminino, diferenciando-o do sexo biologicamente definido. É neste contexto também que passam a aparecer teorias de caráter efetivamente sociológico para analisar a delinquência feminina e a visível desproporção da criminalização entre os sexos.

Até aqui não se contestava o papel da mulher no âmbito privado, sendo que os cuidados domésticos eram entendidos como sua função natural da mesma. Assim, com esta nova perspectiva de gênero, é possível observar a socialização diferenciada que constrói o feminino e o masculino, com seus estereótipos pré-determinados.

\footnotetext{
6 O texto em língua original diz: "La baja tasa de criminalidad femenina podría explicarse como una consecuencia simultánea, tanto de una actividad criminal sumergida como de su favorable consideración social, de tal manera que si bien su criminalidad no suele ser detectada policialmente en aquellos casos en que se denuncia, se la otorga un trato más favorable que al varón por parte del "Sistema de Justicia Penal" - práctica conocida como caballerosidad" (MURILLO, 1990, p. 71)

7 Butler diz que: "Originalmente con el propósito de dar respuesta a la afirmación de que biología es destino, esa diferenciación (sexo y género) sirve al argumento de que, con independencia de la inmanejabilidad biológica que

tenga aparentemente el sexo, el género se construye culturalmente: por esa razón el género no es el resultado causal del sexo ni tampoco es

$\tan$ aparentemente rígido como el sexo."
} 
Estes primeiros estudos sociológicos do desvio tiveram diferentes enfoques. O enfoque funcionalista, que trabalha com a "teoria do rol", a qual se fixa nos papéis atribuídos para os diferentes sexos, sendo que para que a mulher possa romper com a norma legal deve romper antes com suas normas morais, e com todos os seus papéis de mãe, esposa e responsável do lar, estabelecidos socialmente. É inegável e visivelmente perceptivo um controle muito maior sobre a mulher e, nesse sentido aponta-se uma maior dificuldade para ela chegar a cometer um delito tipificado legalmente.

Os estudos que se ocupam da delinquência feminina desde a perspectiva da teoria do rol, se agrupam em duas grandes correntes: a teoria da reversão do rol e a teoria da convergência do rol. Para a reversão do rol se considera que a mulher, influenciada pelos movimentos de libertação, vai romper com seus papéis tradicionais e aproximar-se dos índices de delinquência masculina, enquanto que para a teoria da convergência de rol há uma defesa em prol da semelhança entre a criminalidade masculina e feminina, a qual vai se dar com uma aproximação entre os papéis de ambos: uma masculinização dos papéis femininos e uma feminização dos masculinos (SERRANO TÁRRAGA Y GONZÁLEZ, 2006).

Também a respeito do enfoque funcionalista, temos a teoria das oportunidades, defendida pela autora Freda Adler (1975). Essa corrente aduz que a mulher não tem as mesmas oportunidades que o varão para delinquir, uma vez que, em razão da sua socialização, ela é mantida no âmbito privado e dentro do espaço doméstico.

Para todas estas perspectivas de enfoque funcionalista, as mulheres, por influência dos movimentos libertários feministas, alcançariam as mesmas taxas de delinquência dos homens assim que assumissem novos papéis na sociedade, rompessem seus estereótipos, participassem da vida pública e do espaço laboral. Todavia, esta proposição não se confirmou com o passar dos anos.

Como consequência, tem-se que mesmo com uma superior participação da mulher na vida pública, seus indicies de criminalização seguem inferiores e inclusive semelhantes aos da época em que tinham representação pública quase nula, conforme se vai demonstrar mais adiante com apreciação das estatísticas.

Finalmente, temos os enfoques críticos dos estudos de caráter sociológico. No que se refere à criminalidade feminina, o enfoque crítico centra-se nos controles informais e formais exercidos sobre a mulher.

Assim, se constata que há muitas instituições antes do Estado controlando as condutas femininas desde a infância, na família e na escola, o que sujeita a mulher a muitas 
barreiras morais, dificultando seu acesso a delinquência. O que se conclui, portanto, é que sobre a mulher não incide apenas os controles formais, se não muitos controles informais, os quais fazem com que tenha que corresponder às expectativas sociais determinadas para o seu gênero, por temer os julgamentos morais. Por essa razão, as mulheres cometeriam menos delitos, uma vez que se têm muitas outras normas para romper até chegar às normas legais impostas pelo Estado. Assim sendo, passa-se a perquirir a respeito da (des)vantagem desta menor criminalização.

\section{UMA MENOR CRIMINALIZAÇÃO REPRESENTA VANTAGEM PARA AS MULHERES? UMA APROXIMAÇÃO DA CRIMINOLOGIA CRÍTICA E DO FEMINISMO}

Se há um argumento incontestável em todas as teorias brevemente relacionadas acima, é o de que a mulher não comete, em nenhum período histórico-social, tantos delitos quanto o homem. Ademais, se pode deduzir também, da apreciação das teorias, que o controle penal sempre foi dirigido para a mulher que não correspondia às expectativas sociais atribuídas ao seu gênero. A mulher é "anormal": possui distúrbios hormonais, genéticos ou de formação cerebral para os estudos biológicos, é "louca" para os estudos psiquiátricos, etc.

São os estudos feministas que auxiliam para se chegar a uma percepção da necessidade da compreensão de gênero como algo construído e não natural, o qual se deposita toda a expectativa que vai ser controlada de maneira informal pela sociedade.

Todavia, a contribuição dos movimentos feministas para as primeiras teorias de perspectiva social - de caráter funcionalista- , não foi suficiente para explicar a grande diferença entre as taxas de criminalização feminina e masculina.

Mesmo com a maior emancipação feminina, e sua participação na vida pública, até hoje os níveis de condutas delitivas das mulheres é brutalmente inferior que o dos homens. Isso fica muito claro quando analisamos as estatísticas da população presa no Brasil nos últimos anos:

População reclusa no Brasil. Até 2012 


\begin{tabular}{|c|c|c|c|c|c|}
\hline \multicolumn{6}{|c|}{ Población reclusa } \\
\hline \multicolumn{6}{|c|}{ População reclusa por sexo e período. } \\
\hline \multicolumn{6}{|c|}{ Unidades:número de reclusos } \\
\hline & & & & & \\
\hline & & & & & \\
\hline & 2008 & 2009 & 2010 & 2011 & 2012 \\
\hline \multicolumn{6}{|l|}{ TOTAL } \\
\hline Ambos sexos & 451.429 & 473.626 & 496.251 & 514.582 & 548.003 \\
\hline Homens & $\begin{array}{r}422.775 \\
(94 \%)\end{array}$ & $\begin{array}{r}442.225 \\
(93 \%)\end{array}$ & $\begin{array}{r}461444 \\
(93 \%)\end{array}$ & $\begin{array}{r}480524 \\
(93 \%)\end{array}$ & $\begin{array}{r}512964 \\
(94 \%)\end{array}$ \\
\hline Mulheres & $28.654(6 \%)$ & $\begin{array}{r}31.401 \\
(7 \%)\end{array}$ & $\begin{array}{r}34.807 \\
(7 \%)\end{array}$ & $\begin{array}{r}34.058 \\
(7 \%)\end{array}$ & $\begin{array}{r}35.039 \\
(6 \%)\end{array}$ \\
\hline $\begin{array}{l}\text { Fonte: Tabela fe } \\
\text { PENITENCIÁRIO } \\
\text { ano 2013. }\end{array}$ & com os dado & $\begin{array}{l}\text { S do MINISTÉR } \\
\text { a Integrado de In }\end{array}$ & $\begin{array}{l}\text { IO DA JUS } \\
\text { formações F }\end{array}$ & $\begin{array}{l}\text { IIÇA DEPA } \\
\text { enitenciária }\end{array}$ & $\begin{array}{l}\text { IAMENTO } \\
\text { - InfoPen, }\end{array}$ \\
\hline
\end{tabular}

Analisando-se a tabela acima, é possível verificar que, nos últimos quatro anos relacionados, a porcentagem de mulheres presas não passa de $7 \%$ do total, respeitando o gender gap já referido neste trabalho.

O que se percebe, portanto, é que apesar de já possuírem um lugar na vida pública, política e laboral, é recorrente o fato de a mulher seguir com seus deveres de cuidado, dando mais importância à família e julgadas socialmente por sua postura e suas condutas. Isso é o que, em linguagem coloquial, se permite hoje de qualificar de "super-mulher: a trabalhadora, a ama de casa, a carinhosa, a sedutora, a esposa, a esportista, entre outros" (VILLA 2013, p. 48).

Neste sentido, o que se denota destes índices conjugados com o estudo sociológico do delito, é que a mulher é menos infratora, mas isso pode significar usufruir menos de liberdades sociais (Villa, 2013). Isso porque a mulher não está livre estando fora do cárcere. Seu controle não é garantido apenas pelas normas legais, pois há muitas outras normas sociais que necessitam romper, antes de cometer um crime.

Essas normas sociais são reflexo de uma relação de dominação e da divisão entre os sexos, que parece estar "na ordem das coisas", como se diz às vezes para falar do que é normal, ao ponto de ser inevitável (BOURDIEU, 2012, p.72).

Conforme refere Bordieu (2012), quando ressalta as denúncias da continuidade desta relação mais íntima que a mulher mantém com os deveres familiares:

A verdade das relações estruturais de dominação sexual se deixa realmente entrever a partir do momento em que observamos, por exemplo, que as mulheres que 
atingiram os mais altos cargos (chefe, diretora em um ministério etc.) têm que "pagar" de certo modo, por este sucesso profissional com um menor "sucesso" na ordem doméstica (divórcio, dificuldade com os filhos,etc.); ou, ao contrário, que o sucesso na empresa doméstica tem, muitas vezes, em contrapartida, uma renúncia parcial o total ao maior sucesso profissional (BOURDIEU, 2012, p. 127).

Para garantir esta dominação, estão os controles exercidos pelas famílias, escolas e a sociedade. Mesmo que menos agressivo e incidente que no passado, ainda se limita a subversão da mulher, socializando-a na submissão, mais do que o homem (Villa 2013, 41).

Esta socialização em um binarismo de gênero, de relação constante entre a natureza e a cultura, o que, conforme explica Butler (2014), fomenta uma relação hierárquica:

\begin{abstract}
Não obstante, a consideração mesma de sexo-como-matéria, sexo-comoinstrumento-de-significação-cultural, é uma formação discursiva que opera como uma base naturalizada para a diferenciação entre natureza/cultura e as estratégias de dominação que é distinção solene. A relação binária entre cultura e natureza fomenta uma relação hierárquica em que a primeira livremente "exige" um significado a segunda e, por esse motivo converte em um "outro" que se adéqua a seus próprios usos ilimitados, protegendo o ideal do significante sobre o modelo de dominação" (BUTLER, 2014, p.104).
\end{abstract}

Desta maneira, os papéis atribuídos à mulher como ama de casa, esposa e mãe reduzem as possibilidades para que ela cometa delitos. O espaço livre da mulher está muito reduzido por normas e costumes da moral tradicional. A atividade profissional que hoje lhe é possibilitada, normalmente vem complementada pelo desenvolvimento de atividades domésticas e responsabilidades familiares, com os respectivos julgamentos morais ligados a estes encargos.

Assim, estes controles informais exercidos atuam de forma eficaz, o que permite que poucas mulheres cheguem às instâncias do controle formal, integradas pelas instituições policiais judiciais, penitenciárias ou clínicas (psiquiátrica) (SERRANO TÁRRAGA Y GONZÁLEZ, 2006).

Deste modo, o sistema de justiça criminal funciona como um mecanismo público adjunto ao controle informal dirigido a mulher, que reforça o controle patriarcal (a estrutura e o simbolismo de gênero), pois "criminaliza as mulheres em situações específicas e, soberanamente, reconduz ao lugar de vítima, mantendo-as em seu lugar passivo"(ANDRADE, 2012, p.132).

Há uma preocupação especial com a defesa da sociedade e da família tradicional, se tratando, no Direito penal, de um controle que se apresenta mais como uma nova modalidade de controle exercido sobre as mulheres, uma instância na qual se reproduzem e intensificam suas condições de opressão, através de um padrão de normalidade (ESPINOZA, 2012). 
Além disso, romper com mais de um controle, até chegar à delinquência, significa sofrer mais de uma pena. As mulheres condenadas não são apenas julgadas legalmente, mas sofrem uma dupla reprimenda. Conforme afirma Murillo (1990):

\begin{abstract}
É assim que a delinquência feminina aparece definida por uma dupla anormalidade biológica e social- que apresenta sua criminalidade como uma prática masculinizada e imprópria do seu sexo. Esta dupla concepção provoca, a sua vez, uma dupla repulsa, de maneira que a condena legal se acrescenta uma "condena social", que não ocorre com o varão. ${ }^{8}$ (MURILLO, 1990, p. 59).
\end{abstract}

Essa continuidade, ou melhor, perpetuação dos sistemas de controle - em que a lógica penal vai relegitimar os valores do controle patriarcal - leva a mulher crer que o seu papel é inerentemente maternal. Ao desviar da norma legal, ela não cometeu apenas um delito, mas um "pecado", que justifica a sua condenação por parte do Estado e de seus familiares. Uma multiplicidade de penas que supõe um dever único com a família.

O que fica claro, portanto, é que - principalmente para as mulheres- estar fora do cárcere não significa liberdade. São controladas e julgadas, sem a necessidade de cometer um crime legalmente estabelecido. As redes de controle que atuam sobre a mulher são as responsáveis pelos baixos índices de crimes cometidos por elas. É dizer, que elas não têm as mesmas condições de optar livremente por delinquir que têm os homens, porque estão cotidianamente sendo observadas para que cumpram com seus deveres de mãe, esposa e mulher.

Ademais, quando chegam a ser selecionadas pelo controle penal, e efetivamente condenadas por um delito, sua condenação é geralmente superior a de igual delito cometido por um homem. Isso porque vai sofrer com os rótulos do fracasso no seu papel de mulher.

Dessa forma, longe de ocupar duas esferas hermeticamente separadas, a crítica do controle penal e a crítica feminista ao domínio masculino heterossexual, se encontram entrelaçadas de modo que o controle (informal) exercido pela sociedade sobre as mulheres, é continuado pelas instâncias formais do Direito Penal.

\footnotetext{
8 O texto em língua original refere: "Es así como la delincuencia femenina aparece definida por una doble anormalidad -biológica y social - que presenta su criminalidad como una práctica masculinizada e impropia de su sexo. Esta doble concepción provoca, a su vez, una doble repulsa, de manera que a "la condena legal" se añade también una "condena social", que no ocurre con el varón" (MURILLO, 1990 , 
Tem razão Baratta quando se pergunta: Porque havendo sido contemporâneos, a aparição das teorias de reação social e o feminismo não se aproveitaram mutuamente? Uma criminologia crítica deve questionar o Direito Penal e a seletividade de gênero com que opera" (BARATTA, 2000, p. 60).

Em seguimento, passa-se a verificação da política criminal antidrogas e perspectiva de gênero.

\section{POR QUAIS DELITOS SÃO MAIS CRIMINALIZADAS? A POLÍtica CRIMINAL ANTIDROGAS E A PERSPECTIVA DE GÊNERO}

As políticas penais focadas no castigo já fazem parte de uma cultura penal específica, que suporta a si mesma graças às formas culturais mais amplas, que por sua vez se baseiam em padrões de vida material e ações sociais da sociedade (DÍAZ CORTÉS, 2009).

Essa cultura fica clara quando refletida nas estatísticas de encarceramento e uma observação qualitativa sobre a tipologia dos delitos mais presentes nas condenações e reclusões. Relacionando os dados do ano de 2012, do informe da Comissão interamericana de Direitos Humanos (2013) é possível identificar o alarmante índice de condenações por tráficos de drogas.

Com atenção especial a situação brasileira, percebe-se que o delito de maior incidência na população penal em geral - de acordo com o número de condenações - é o tráfico de drogas (não internacional), com 127,149 pessoas no total, sendo que deste número $79 \%$ são homens $(110,965)$ e $11 \%$ mulheres $(16,184)$. Os demais delitos que se destacam são o roubo qualificado (total de 94,447, sendo 92,602 homens e 1,845 mulheres), furto simples (total de 36,671, sendo 35,608 homens e 1,603 mulheres) e homicídio qualificado $(34,463$, sendo 33,536 homens e 927 mulheres).

É perceptível a massiva condenação pelos delitos ligados ao tráfico em ambos os sexos. Todavia, com enfoque na criminalização feminina, se destaca desse contexto a alta porcentagem de mulheres encarceradas no Brasil pela ligação com entorpecentes.

Isso fica claro quando verificado que se do total de mulheres presas no ano de 2012 foi de 35,039, e o número de 16,184 são reclusas pelo delito de tráfico de drogas tem-se uma representação de proporção aproximada de $46 \%$ da população carcerária feminina criminalizada pelo mesmo delito. 
A política penal em matéria de drogas é repressiva, resultando nesta grande população de centros penitenciários cumprindo pena por delitos de tráfico de drogas. Além de penas altas e uma política muito dura para reprimir o tráfico, é muito recorrente identificar como delito qualquer conduta envolvendo o manejo com as drogas, recaindo uma repressão exagerada, principalmente sobre o público mais vulnerável.“ Há se convertido a droga na "responsável" por todos os males que afligem o mundo contemporâneo porque a própria palavra esta funcionando como estereótipo mais do que como conceito; como crença, mais do que como descoberta cientifica pesquisada" (DEL OMO 1990, 51).

Por tudo isso, pode-se afirmar que a política repressiva em matéria de drogas afeta de forma realmente significativa o coletivo feminino (Puente Alba 2012, 100). Em situação de vulnerabilidade, muitas vezes a mulher assume a atividade do tráfico como fonte de sustento familiar, tornando-se também alvo de esta política (guerra) contra as drogas.

Estes fatos tornam evidente a criação de um mercado negro de drogas, através da criminalização do tráfico, que obviamente gera um aumento importante dos preços e propicia a alteração das substâncias; a consolidação de amplas redes ilegais dedicadas ao tráfico de drogas, com uma estrutura que provoca que sejam os elos mais inferiores e mais fracos que levem a cabo as condutas mais arriscadas (PUENTE ALBA, 2012: 211).

No tráfico se encontra uma maneira alternativa para a falta de oportunidade e desigualdade social, buscando sustento de maneira arriscada. Principalmente para quem assume as atividades mais suscetíveis de serem descobertas e castigadas: transporte da droga, pequenas vendas, empacotamento da mercadoria, etc. Se pensamos nas mulheres com cargas familiares, sem trabalho remunerado, sem formação que permita ascender facilmente um posto de trabalho, a participação num mercado negro de drogas surge como uma possível via de escape para obter rapidamente ingressos econômicos (PUENTE ALBA, 2012: 112).

É dizer, o cárcere afeta, de maneira extensa e desproporcional, o perfil de pessoas pertencentes a grupos economicamente mais vulneráveis, que em geral encontram obstáculos no acesso a outras medidas cautelares, como a fiança, pois sequer podem arcar com os gastos que implicam o enfrentamento de um processo penal.

Essa variável do perfil de classe social deve ser acrescentada a outras, na relação das mulheres criminalizadas. No que se refere à aplicação da lei penal ao grupo feminino, se pode destacar o que diz a professora Carmen Campos (2002): 
Mas a questão também deve ser confrontada internamente, entre as mulheres: que mulheres a lei exclui ou prejudica? São as mulheres brancas ou negras? O prejuízo legal é o mesmo para as mulheres em desvantagem econômica? Dessa forma,evitase o essencialismo e se reconhece que o gênero é um dos marcadores que, associado a outros (raça/etnia, situação econômica, educação, etc.), confere diferentes opressões ou subordinações às mulheres" (CAMPOS, 2002, p. 8.).

Assim, é nítido que estas duras políticas criminais atingem principalmente - se não apenas- a parte mais vulnerável da sociedade. Se houver uma atenção, mesmo que rápida para o perfil destas mulheres presas, é possível perceber que, segundo os dados do DEPEN (Departamento Penitenciário Nacional), no ano em análise, a maior parte das mulheres é primária $(72 \%)$ em seus atos delituosos, enquanto que $44 \%$ dos homens se dizem reincidentes.

Normalmente, as mulheres, são negras (54\%). A proporção de 87,3\% delas têm filhos, sendo que a média de seus filhos é de 2 anos. A maioria dessas mulheres não tem um alto nível de educação, sendo que 66,4\% tem escola básica incompleta, inclusive sem saber ler e escrever. Uma proporção de 70,8\% das mulheres criminalizadas exerciam trabalhos domésticos para outras pessoas, trabalhavam com lixo ou prostituição, e 22,7\% não tinham nenhuma renda econômica (DEPEN, 2013)

Outra crítica à adoção desta postura política é o fato de que o uso de tóxicos estaria dentro do limite de uma liberdade individual das pessoas. É perguntar-se: que efeitos reais o uso individual de drogas causa para terceiros? Conforme estipula o Professor Garcia (2013), a respeito dos limites de atuação penal:

Um determinado fato ou fenômeno deve ser definido como problema social apenas se concorrem nele as seguintes circunstancias: que tenha uma incidência massiva na população; que tal incidência seja dolorosa e aflitiva; persistência no espaço temporal; a falta de um inequívoco consenso a respeito de sua etiologia, eficazes técnicas de intervenção no mesmo e consciência social generalizada de sua negatividade. Assim, deve afetar toda a sociedade e não apenas a quem o padece"

(GARCIA, 2013, p.50)

Neste sentido, há que se questiona: O uso da droga afeta a todos? Ou apenas ao indivíduo que a consome? O tráfico de drogas, em verdade, está criado por esta política criminal que criminaliza o alcance da droga ao usuário. É necessário e urgente refletir até que ponto é mais prejudicial para a sociedade o uso das drogas pelos indivíduos - em gozo da sua liberdade individual- do que esta dura política criminal contra as drogas, que é responsável pela maior parte das pessoas presas nos últimos anos amontoados como seres (não) humanos.

Diante das exposições acima, passa-se a conclusão.

9 O texto em língua original refere: "Un determinado hecho o fenómeno debe ser definido como problema social sólo si concurren en él las siguientes circunstancias: que tenga una incidencia masiva en la población; que dicha incidencia sea dolorosa, aflictiva; persistencia espacio temporal; falta de un inequívoco consenso a respecto a su etiología, eficaces técnicas de intervención en el mismo y conciencia social generalizada a su negatividad Afecta a toda la sociedad, no sólo a quien lo padece. (GARCIA, 2013, p.50) 


\section{CONCLUSÃO}

As reflexões a respeito da diferença nas taxas de delinquência entre homens e mulheres sempre foram escassas, uma vez que o número de mulheres criminalizadas nunca teve grande representatividade. Ainda assim, os estudos a respeito - apresentados brevemente neste artigo - deixaram muitas explicações para o "gender gap" da criminalização, que em regra, sustentaram a anormalidade da mulher desviada.

A imagem da mulher delinquente deixa de ser relacionada como um ser incapaz apenas com a ascensão dos movimentos feministas de libertação, nos fins dos anos 70. Ainda assim, as primeiras explicações que adotam o conceito de gênero em sua teoria, não lograram êxito em suas justificativas em relação a avaliação do baixo índice de cometimento de delitos pelas mulheres. Isso porque, essas primeiras teorias, de caráter funcionalista, estabeleciam uma relação entre a emancipação da mulher e sua participação nas atividades delitivas. É dizer, a mulher, que começava a ter mais direitos e liberdades, teria menos estereótipos femininos, mais espaços no âmbito público, e, assim, mais oportunidades para delinquir.

Entretanto, observando os dados atuais, se verifica que esta teoria necessita ser compreendida em conjunto com a teoria critica do controle penal, uma vez que, mesmo com uma maior participação pública das mulheres, estas seguem com os mesmo índices delitivos de outrem.

Mesmo com a conquista de espaço público, os estereótipos impostos pelo sistema patriarcal seguem dominantes. Isso porque, apesar da mulher trabalhar fora, seguem suas as principais responsabilidades domésticas e o dever maior com a família. São estes estereótipos e o dever de cuidado da mulher que a afastam do cometimento de delitos, razão pela qual delinquem menos.

Portanto, com a perspectiva crítica que se adota neste trabalho, o que se conclui é a clara relação convergente entre o patriarcal e o penal, fazendo necessária uma aproximação da criminologia crítica e do feminismo, isso porque, se estes estereótipos de gênero - que se busca abolir - são os responsáveis por afastar a mulher da prisão, a criminologia crítica é essencial para a luta feminista pela liberdade das mulheres. Fica claro que o controle penal visa direcionar o castigo não apenas pelo crime que cometeu, se não também culpabilizá-la por seu fracasso social como mulher, buscando reeducá-la pelas normas do sistema patriarcal dominante. 
Neste ponto que convém questionar-se a respeito da existência de benefícios em ser, a mulher, menos criminalizada pelo Estado. Com este breve trabalho, é possível perceber que, em verdade, a mulher não está em situação de vantagem apenas pelo fato de estar menos encarcerada. Em realidade, está aprisionada em seu gênero e nas expectativas que surgem dele, sendo controlada em todas as esferas públicas e privadas.

Ainda assim, mesmo com todas as barreiras impostas pelas normas atribuídas a seus gêneros, algumas mulheres são selecionadas pelo controle criminal. É neste contexto em que se destaca a massiva criminalização pelo crime de tráfico de drogas.

As últimas estatísticas demostram que a política criminal contra as drogas está cada vez mais dura, fazendo verdadeiros inimigos de guerra qualquer um que tenha um envolvimento com entorpecentes. Todavia, em realidade, estas políticas criminais vão atingir sempre a parcela mais vulnerável da sociedade, não sendo efetiva para diminuir o uso de drogas, se não apenas como instrumento para a criminalização de minorias.

Não apenas este argumento serve para questionar tais políticas criminais, mas também o fato de que o delito de tráfico de drogas envolve a criminalização de uma compra por quem deseja o entorpecente, no uso de suas liberdades individuais. O direito penal não deveria, em regra, controlar os efeitos dos atos de liberdade individual que não afetem terceiros.

Assim, no que se refere ao último objetivo indicado pelo trabalho, se conclui pela necessidade de refletir a respeito de que se a política criminal contra as drogas - que atinge de maneira crucial a população feminina- não é ainda mais prejudicial para a sociedade que o próprio uso de drogas.

\section{REFERÊNCIAS}

ABREU, María Luisa Maqueda. Razones y sinrazones para una criminología feminsta. $1^{\mathrm{a}}$ edición. Madrid: Dykison S.L., 2014.

ADLER, Freda. Sisters in Crime. The rise of the new female criminal. New York: MacGrawHill, 1975.

ANDRADE, Vera Regina Pereira. Do paradigma etiológico ao paradigma da reação social: mudança e permanência de paradigmas criminológicos na ciência e no senso comum. Revista CCJ/UFSC, n. 30, ano 16, p. 24.36, junio 1995. 
.Pelas mãos da criminologia: O controle penal para além da (des)ilusão. $1^{\mathrm{a}}$ edición. Rio de Janeiro: Revan, 2012.

BARATTA, Alessandro. Viejas y nuevas estratégias en la legitimación del Derecho penal. Poder y Control. Barcelona, PPU, nº, pp. 77-92, 1986.

. O paradigma de gênero: da questão criminal à questão humana. En CAMPOS, Carmen Hein. coord. Criminologia e feminismo. Porto Alegre: Sulina, 2000. p.21.

BEAN, Robert Bennett, American Anthropologist, New Series, Vol. 48, No. 1, Jan. - Mar., 1946, p. 70-74.

BORDIEU, Pierre. A dominação masculina. $11^{\text {a }}$ edição. Rio de Janeiro: Bertrand Brasil, 2012.

BRASIL. Departamento Penitenciario Nacional. Mulheres Presas Dados Gerais. Projeto Mulheres DEPEN - 2013.

. Ministério Da Justiça Departamento Penitenciário Nacional. Sistema Integrado de Informações Penitenciárias - InfoPen, ano 2013

BROCA. Sur le principe des localisations cérébrales. Bulletin de la Société d"Anthropologie 1861, p. 190-204

BUTLER,Judith. El género en disputa. 6ª edición. Barcelona: Paidros, 2014.

CAMPOS, C. H. (Org.) . Criminologia e Feminismo. 1. ed. Porto Alegre: Sulina, 1999. 120p . Razão e Sensibilidade: Teoria Feminista do Direito e Lei Maria da Penha, Porto Alegre: 2002.

CIDH, Comisión Iteramericana de Derechos Humanos. Informe sobre el uso de la prisión preventiva en las Américas, 2013.

DEL OLMO, Rosa. A face oculta da droga. Rio de Janeiro: Revan, 1990.

DÍAZ CORTÉS, Lina Mariola. Consideraciones sobre el castigo: una perspectiva desde la sociología. $1^{\text {a }}$ edición. Bogotá: Leyer, 2009.

ESPINOZA, Olga. A prisão feminina desde um olhar da criminologia feminista.Revista Transdisciplinar de Ciências Penitenciárias, 1(1), Jan-Dez./2002: 35-59.

GÁRATE, Justo. La covada pirenaica. Patrañas y fantasías, 2011.

GARCIA, Fernando Santa Cecília.Objeto de la Criminología (I). Delito y delincuente. En PÉREZ ÁLVAREZ, Fernando y DÍAZ CORTÉS, Lina mariola. Introducción a la Criminología. Salamanca: RATIO LEGIS, 2013, 49-57.

LOMBROSO, Césare y FERRERO, G. La donna Delinquente, la prostitua e la donna normale. Quinta Edizione,1927. 
MATOS, Deborah Dettmam. Racismo científico: O legado das teorias bioantropológicas na estigmatização do negro como delinqüente. In: Âmbito Jurídico, Rio Grande, XIII, n. 74, mar 2010. Disponível em: <http://www.ambitojuridico.com.br/site/index.php?n_link=revista_artigos_leitura\&artigo_id=7448>. Acesso em ago 2015.

MURILlO, A.C. Delincuencia femenina en España. Madrid: Centro de Publicaciones del Ministerio de Justicia, 1990.

POLLACK, O.: The Criminality of Women, New York: A. S. Barnes, 1961.

PUENTE ALBA, Luz María. Perspectivas de género en las condenas por tráfico de drogas. Oñati Social-Legal Series, 2012, v.2(n.6): 97-121.

RODRÍGUEZ, Juan Antonio. Criminología y Género: comentarios a partir del gender gap. Capítulo Criminológic, 2009. vol. 37. Núm. 4: 161-182.

SERRANO TARRAGA, Ma Dolores Serrano, y GONZÁLEZ,Carlos. Delincuencia femenina: Nuevas perspectivas para su estudio. Cuadernos de Política Criminal. Noviembre de 2006.Núm. 90: 159-198.

SMART, Carol. Woman, Crime and criminology. A feminist critique. London: Routledge\&Kegan Paul Ltda, 1976.

TARNOWSKY, Pauline Etudes anthropométriques sur les prostitués et les voleuses. Bulletins de la Société d'anthropologie de Paris 1889

THOMAS, W. I. The unadjusted girl. With cases and standpoint for behavior analysis. New York, Harper and Row: 196

VILLA, Fernando Gil. Introducción a las teorías Criminológicas: Por qué rompemos con la norma. Madrid: Tecnos, 2013. 